\title{
Dos aprendizados agrícolas às escolas agrotécnicas: a gênese da Escola Agrotécnica Federal Dom Avelar Brandão Vilela em Petrolina-PE, no contexto histórico do ensino técnico federal no Brasil
}

\author{
From agricultural apprenticeships to agrotechnical schools: the genesis of \\ Dom Avelar Brandão Vilela federal agrotechnical school in Petrolina-PE, in \\ the historical context of federal technical education in Brazil
}

\author{
Inês Silva Guimarães \\ Mestranda em Educação, Cultura e Territórios Semiáridos \\ Universidade do Estado da Bahia - UNEB. \\ Juazeiro, Bahia - Brasil. \\ inessguimaraes@gmail.com \\ Dosé Roberto Gomes Rodrigues \\ Doutor em Educação \\ Universidade do Estado da Bahia - UNEB \\ Juazeiro, Bahia - Brasil. \\ jrrodrigues@uneb.br
}

Resumo: O artigo tem como objetivo analisar o contexto no qual foi idealizada e concretizada a implantação da Escola Agrotécnica Federal Dom Avelar Brandão Vilela, em Petrolina (PE), no ano de 1988, a possível relação com a institucionalização da forma de ensino técnicoprofissional no Brasil e, especificamente, do ensino agrícola. Tal análise é realizada a partir dos conceitos de campo e de formas de escolarização, numa perspectiva relacional e sócio-histórica, por meio de pesquisa bibliográfica e documental. $\mathrm{O}$ artigo aborda as raízes do ensino técnico no Brasil, as relações escravistas e força de trabalho; as Escolas de Aprendizes Artífices e a normatização do ensino agrícola; as Escolas Agrotécnicas Federais, concluindo com a ideia de que é possível perceber uma confluência de elementos na gênese desta instituição e da Escola Dom Avelar Brandão Vilela.

Palavras chave: ensino agrícola; escola agrotécnica; formas de escolarização; história da educação.

Abstract: The article aims to analyze the context in which the Dom Avelar Brandão Vilela Federal Agrotechnical School was conceived and implemented in Petrolina (PE) in 1988, and the possible relationship with the institutionalization of technical-vocational education in Brazil and, specifically, of agricultural education. This analysis is carried out based on the concepts of field and forms of schooling, in a relational and sociohistorical perspective, by means of bibliographic and documental research. The article approaches the roots of technical education in Brazil, the slave and labor force relations; the Schools of Apprentice Artisans and the standardization of agricultural education; the Federal Agrotechnical Schools, concluding with the idea that it is possible to perceive a confluence of elements in the genesis of this institution and the Dom Avelar Brandão Vilela School.

Key-words: agricultural education; agrotechnical school; forms of schooling; history of education.

Cite como

(ABNT NBR 6023:2018)

GUIMARÃES, Inês Silva; RODRIGUES, José Roberto Gomes. Dos aprendizados agrícolas às escolas agrotécnicas: a gênese da escola agrotécnica federal Dom Avelar Brandão Vilela em Petrolina-PE, no contexto histórico do ensino técnico federal no Brasil. Dialogia, São Paulo, n. 39, p. 1-17, e20761, set./dez. 2021. Disponível em: https://doi.org/10.5585/39.2021.20761.

\section{American Psychological Association (APA)}

Guimarães, I. S., \& Rodrigues, J. R. G. (2021, set./dez.) Dos aprendizados agrícolas às escolas agrotécnicas: a gênese da escola agrotécnica federal Dom Avelar Brandão Vilela em Petrolina-PE, no contexto histórico do ensino técnico federal no Brasil. Dialogia, São Paulo, 39, p. 1-17, e20761. https://doi.org/10.5585/39.2021.20761. 
Introdução

A Escola Agrotécnica Federal Dom Avelar Brandão Vilela foi criada em 1988, em Petrolina (PE), região do Submédio São Francisco, através do decreto presidencial nº 96.598. Localizada na zona rural do município, a unidade tinha como objetivo "constituir-se em um centro de educação rural com vistas ao crescimento da agropecuária local e regional” (BRASIL, 1988).

Para compreendermos o contexto no qual foi idealizada e concretizada a implantação da referida Escola Agrotécnica, é necessário voltarmos no tempo para analisar de que maneira ocorreu a institucionalização da forma de ensino técnico-profissional no Brasil e, especificamente, do ensino agrícola.

Partindo da ideia de campo, no sentido de um espaço simbólico de forças e de lutas que estruturam as interações, determinam e legitimam representações, e a partir da perspectiva de análise relacional (BOURDIEU, 2004, 2012), em que se considera que o objeto em questão não está isolado de um conjunto de relações, pretende-se realizar um estudo introdutório sobre aspectos da estruturação da educação técnica em âmbito nacional e possíveis homologias com a gênese da já mencionada Agrotécnica.

Ter a dimensão do campo educacional em geral é importante para alcançar questões que poderiam passar despercebidas sem essa apreensão, pois "permite um conhecimento do caso particular em profundidade e contribui, também, para captar os movimentos, as tensões, os conflitos" (RODRIGUES, J., 2009, p.102), assim como as relações que se desenvolvem no interior do campo.

Bourdieu (2012) aponta a busca pela gênese de determinada estruturação como uma forma de compreensão da realidade a que se refere. Nesse sentido, o autor apresenta contribuições ao campo da história ao demonstrar a importância da investigação da história social dos problemas, dos objetos sociais. Para o pesquisador José Roberto Gomes Rodrigues (2009), cujos estudos são desenvolvidos a partir da sócio-história, a pesquisa destes objetos sociais - as instituições escolares - se assemelha ao ofício do alquimista, no sentido da busca por sua essência. "É como se a história operasse como um alquimista, que extrai a sua quintessência e o seu substrato ou o que há de mais essencial nela contido, pois, de outra forma, ficaria difícil o entendimento e a compreensão do objeto ou da realidade a que se reporta" (RODRIGUES, 2009, p. 57).

Dessa forma, este estudo demonstra importância no campo da história da educação, no sentido de compreensão dos movimentos da educação em determinados períodos de tempo e espaço, rompendo com a ideia que oculta a historicidade do pensar e fazer educacional, que termina impedindo "a compreensão da forma como se construíram os discursos científicos na arena 
educativa em simultâneo com o desenvolvimento de grupos profissionais e de sistemas especializados de conhecimento" (NÓVOA, 1996, p. 417). Tal campo, a partir dos estudos e debates que têm se realizado em torno de sua constituição, tem se mostrado fecundo, influente e importante para os campos mais amplos da educação e da história. (RODRIGUES, 2009).

Além dos já mencionados, outro conceito que se faz necessário para a compreensão desta análise é o de formas de escolarização, que "não se definem apenas como uma designação de um tipo de ensino, grau, nível ou ramo, e, portanto, da escola como partes segmentadas" (RODRIGUES, 2009, p. 61), mas sim a partir das dinâmicas que se estabelecem dentro do campo educacional, entre seus agentes e suas práticas, reverberando na amplitude do campo social.

Chapoulie e Briand (1994) apresentam em seus estudos o conceito de forma de escolarização como o conjunto de categorias de análise destinadas à compreensão do funcionamento da instituição e de suas relações com seu contexto, bem como de regras, normas estabelecidas, sejam elas oficiais ou derivadas de relações entre seus agentes e processos institucionais de forma mais ampla e sua legitimidade. Tais aspectos conceituais nos reportam diretamente à cultura escolar para a compreensão da instituição escolar.

No presente artigo, a partir de pesquisa bibliográfica e documental, pretende-se contextualizar o desenvolvimento do ensino técnico-profissional, especificamente do ensino agrícola, suas características, agentes e práticas, em âmbito nacional, descrevendo, dessa maneira, uma forma de escolarização específica, e relacionar com a instituição da Escola Agrotécnica Federal Dom Avelar Brandão Vilela, observando possíveis conexões em suas dinâmicas e percursos fundadores.

Vale ressaltar que o conceito de ensino agrícola, aqui mencionado, difere do conceito de ensino rural. De forma bastante simplificada, enquanto o primeiro refere-se à formação profissional ligada à produção econômica, ao setor agropecuário, o segundo relaciona-se à educação formal propedêutica, no meio rural (SOBRAL, 2004).

Para tanto serão abordadas as raízes do ensino técnico no Brasil, suas relações escravistas e a força de trabalho; as Escolas de Aprendizes Artífices e as primeiras normatizações do ensino agrícola. Em seguida, trataremos sobre as Escolas Agrotécnicas Federais e, por fim, acerca da Escola Agrotécnica Federal Dom Avelar Brandão Vilela.

\section{As raízes do ensino técnico no Brasil: relações escravistas e força de trabalho}

A gênese do ensino de ofícios no Brasil remete à ligação entre as relações escravistas e a força de trabalho. Costumava-se associar ofícios como carpintaria, ferraria e confeitaria, por 
exemplo, à condição de escravo, o que terminava por estigmatizar o trabalho e afastar homens livres. Ainda no século XIX, quando se exigiam contingentes de artífices maiores que os disponíveis, o Estado coagia homens livres sem condições, sociais ou políticas, de opor resistência, miseráveis, órfãos e abandonados em geral, que eram submetidos à aprendizagem de ofícios manufatureiros (CUNHA, 2005).

Entre os anos de 1840 e 1865, foram criadas casas de educandos artífices por dez governos provinciais, utilizando da mesma ideia de formação compulsória de força de trabalho. Criado em 1875, no Rio de Janeiro, o Asilo de Meninos Desvalidos foi considerado entre estas o estabelecimento mais importante. Meninos entre 6 e 12 anos, em estado crítico de pobreza, chegavam ao Asilo por meio de autoridade policial. Lá, recebiam instrução primária, aprendiam ofícios e trabalhavam nas oficinas para pagar sua aprendizagem e formar economias que lhes eram entregues ao fim de três anos de trabalho (CUNHA, 2005).

Enquanto as instituições estatais voltavam-se para a formação compulsória da força de trabalho, iniciativas particulares, como o Liceu de Artes e Ofícios do Rio de Janeiro, fundado em 1858, dedicavam-se à formação de trabalhadores livres.

\begin{abstract}
As iniciativas voltadas para o ensino de ofícios, tanto as do Estado quanto as de entidades privadas, eram legitimadas por ideologias que proclamavam ser a generalização desse tipo de ensino para os trabalhadores livres condição de: a) imprimir neles a motivação para o trabalho; b) evitar o desenvolvimento de idéias contrárias à ordem política, que estava sendo contestada na Europa; c) propiciar a instalação de fábricas que se beneficiariam da existência de uma oferta de força de trabalho qualificada, motivada e ordeira; e d) favorecer os próprios trabalhadores, que passariam a receber salários mais elevados (CUNHA, 2005, posição 89).
\end{abstract}

Ainda que o processo de escravização tenha sido oficialmente abolido no Brasil, em 1888, o ensino de ofícios permaneceu com relações semelhantes às que aconteciam no período imperial, durante o início da República, quando apresentava entre os objetivos para formação de uma força de trabalho qualificada o combate à ociosidade e a organização de padrões sociais de forma que se afastasse dos vícios e dos pensamentos políticos considerados subversivos (CUNHA, 2005).

O ensino profissional, que continuava a ser ofertado aos desvalidos, era visto, por correntes de pensamento positivista e liberal, no início do período republicano, "como uma pedagogia tanto preventiva quanto corretiva", proporcionando o "disciplinamento e a qualificação técnica das crianças e dos jovens", de maneira que evitasse que "fossem seduzidos pelo pecado, pelos vícios, pelos crimes e pela subversão político-ideológica”. Já para quem tivesse sido seduzido por um desses caminhos citados, havia a oficina das escolas correcionais, onde "o trabalho seria o remédio adequado" (CUNHA, 2005, posição 469). 
Já em relação ao ensino agrícola, o marco inicial desta forma de escolarização ocorreu durante o século XIX, com a criação de instituições destinadas a habilitar para o exercício das atividades agrícolas, sendo a primeira delas a Imperial Escola Superior de Agricultura de São Bento das Lages da Bahia (1875). "Este ensino foi ministrado, inicialmente, em patronatos e/ou instituições nitidamente corretivas, porém, essas instituições foram ampliando sua área de profissionalização, através das disciplinas técnicas para a formação de Veterinários, sendo que isso aconteceu de forma muito lenta”. (SOBRAL, 2004, p. 14). Ainda segundo Sobral (2004), é possível afirmar que, durante o século XIX, "não houve uma política de educação sistemática e planejada" (p. 15).

\section{As escolas de aprendizes artífices e a normatização do ensino agrícola}

O cenário econômico, político e social brasileiro, no entanto, passava por mudanças significativas nos primeiros anos do século XX. Com o início do processo de industrialização, que demandava maior quantidade e especialização da mão de obra, iniciaram-se movimentos de escolarização que atuassem com esse fim.

Nesse contexto, de acordo com Cunha (2005), as Escolas de Aprendizes Artífices, criadas pelo presidente Nilo Peçanha, através do decreto 7.566, de 23 de setembro de 1909, foram o acontecimento mais marcante em relação ao ensino profissional no Brasil, na Primeira República.

O decreto indicava a criação de uma Escola em cada uma das capitais dos Estados da República, mantidas pelo Governo Federal, através do Ministério da Agricultura, Indústria e Comércio, e destinadas ao ensino primário profissional e gratuito. Tinham como objetivo formar operários e contramestres, ministrando o ensino prático e os conhecimentos técnicos necessários para aprender um ofício. Os ofícios ensinados deveriam ter ligação direta com as forças econômicas do Estado em que funcionasse a Escola, recomendando-se a consulta, quando possível, às especialidades das indústrias locais (BRASIL, 1909).

Apesar de voltar-se para aspectos econômicos em suas finalidades, o decreto mencionado não deixou de lado os ideais de prevenção, correção e disciplinamento, e justificou a criação das escolas a partir de considerações sobre o aumento constante das populações das cidades e a consequente necessidade de facilitar "às classes proletárias os meios de vencer as dificuldades sempre crescentes da luta pela existência"; sobre a necessidade de habilitar os filhos dos desfavorecidos de fortuna não só ao preparo técnico e intelectual, mas ao hábito do trabalho, "que o afastará da ociosidade ignorante, escola do vício e do crime”, formando cidadãos úteis à nação. (BRASIL, 1909, s/p). 
Chapoulie e Briand (1994) argumentam que a fundação e implantação de novos estabelecimentos é um dos fatores principais para o desenvolvimento da escolarização, o que permite implicar que a criação das Escolas de Aprendizes Artífices contribuiu para a institucionalização do ensino técnico-profissional como uma forma de escolarização, já que no início de 1910, menos de um ano da promulgação do decreto, já estavam "em funcionamento dezenove escolas (em 19 estados), cujas datas de inauguração vão de $1^{\circ}$ de janeiro a $1^{\circ}$ de setembro de 1910” (CUNHA, 2005, posição 1.231), constituindo-se, provavelmente, o primeiro sistema educacional de abrangência nacional.

Com efeito, tratava-se de um agregado de estabelecimentos de ensino, dotados de
propósitos comuns, cujo funcionamento se regulava por uma mesma legislação, além de
estarem afetos à mesma autoridade administrativa e pedagógica. Só muito mais tarde é
que surgiram no país outros sistemas educacionais dotados de características
semelhantes, a exemplo da rede de instituições federais de ensino superior e dos centros
de formação profissional do Senai (CUNHA, 2005, posição 1282).

As Escolas de Aprendizes Artífices tinham seu foco principal na formação de força de trabalho urbano. No ano seguinte à normatização de sua criação, foi publicado o decreto $\mathrm{n}^{\circ}$ 8.319, de 20 de outubro de 1910, que regulamentava o ensino agrícola, a partir de cobranças de setores da agricultura para "implantação do ensino agrícola por parte do governo federal como uma das formas de superar o 'atraso agrícola' em que se encontrava o país” (NERY, 2010, p. 68).

O decreto $\mathrm{n}^{\circ} 8.319$ pode ser considerado marco inicial de uma nova fase de desenvolvimento do ensino agrícola. Vale ressaltar, entretanto, que a maior parte da regulamentação promulgada no período prioriza o ensino superior, "enquanto que o ensino agrícola de nível básico, continua voltado aos filhos de agricultores e aos meninos órfãos e desvalidos da sorte" (SOBRAL, 2004, p. 18).

A normatização tinha por fim a instrução técnica profissional relativa à agricultura e às indústrias correlativas, compreendendo o ensino agrícola, de medicina veterinária, zootecnia e indústrias rurais e abrangendo desde os cursos primários ao ensino superior (BRASIL, 1910). Esta seria "a primeira regulamentação e estruturação do ensino agrícola no Brasil” (SOBRAL, 2009, p. 82) e, a partir dela, buscava-se a organização do ensino agrícola de maneira que abrangesse todo o território nacional, com a centralização no governo federal das políticas de organização e gerenciamento.

Para tanto, era necessário criar instituições de ensino que atendessem à formação em níveis primários, médio e superior. No tocante às instituições de nível primário, o decreto previa a criação dos Aprendizados Agrícolas, que deveriam funcionar atendendo às demandas locais, ou seja, da região que fossem estabelecidos e em conjunto com outras instituições e órgãos que faziam parte da estrutura do ensino agrícola (NERY, 2010, p. 89). 
Os Aprendizados Agrícolas Federais deveriam adotar um ensino voltado para a prática, a partir da ideia do aprender fazendo, e estabelecer uma conexão com a produção e os agricultores locais. Além disso, eram propostos trabalhos em oficinas, seguindo os preceitos das Escolas de Aprendizes Artífices. Ainda em 1910, foram criados três Aprendizados Agrícolas, nos estados de São Paulo, Minas Gerais e Rio Grande do Sul, se constituindo em um marco deste projeto que se estenderá, de maneira instável, por quase toda metade do século XX (NERY, 2010).

Além dos Aprendizados, os Patronatos Agrícolas foram outro modelo de instituição de ensino agrícola primário. No entanto, atrelava formação à regeneração social, tendo essas formas de escolarização agrícola se constituído como formas hegemônicas entre os anos de 1918 e 1934. "Todavia, a maioria dos Patronatos Agrícolas enfatizou muito mais o aspecto corretivo, regenerador, do que o caráter técnico-científico voltado para a modernização agropecuária” (NERY, 2010, p. 188).

A década de 1930 foi de profundas mudanças econômicas, políticas, sociais, no Brasil. Fatos como a criação do Ministério da Educação e Saúde, o desmembramento do então Ministério da Agricultura, Indústria e Comércio em Ministério da Agricultura e Ministério da Indústria e Comércio, a regulamentação das profissões de agrônomo e veterinário causaram transformações também na oferta e regulamentação do ensino profissional agrícola (NERY, 2010).

O Decreto $n^{\circ} 24.115$, de 12 de abril de 1934, que dispunha sobre os estabelecimentos de ensino elementar de agricultura, transformou os Patronatos Agrícolas em Aprendizados Agrícolas, além de criar outras unidades desta natureza, que passaram a ser subordinados à Diretoria do Ensino Agrícola, do Departamento Nacional da Produção Vegetal - Ministério da Agricultura. (BRASIL, 1934). O resultado foi que, a partir desta reforma, passaram a existir dois tipos de Aprendizados: os que haviam nascido como Aprendizado e os que se derivavam dos Patronatos Agrícola. A ideia do Governo Federal era de conferir unidade às instituições solicitando ao Ministério da Educação e Saúde que, para isso, fosse elaborada a Lei Orgânica do Ensino Agrícola (NERY, 2010).

Após este, "vários outros decretos se sucederam, principalmente no período denominado 'Estado Novo', que se estendeu de 1937 a 1945” (NERY, 2010, p. 210). Um deles, o decreto-lei no 2.832, de 4 de dezembro de 1940, criava a Superintendência do Ensino Agrícola e Veterinário (SEAV), que passou a gerenciar o ensino agrícola em níveis elementar e médio.

A Lei Orgânica do Ensino Agrícola (LOEA) seria publicada, no entanto, somente em 20 de agosto de 1946, através do Decreto-Lei no 9.613, estabelecendo "as bases de organização e de regime do ensino agrícola, que é o ramo do ensino até o segundo grau, destinado essencialmente à 
preparação profissional dos trabalhadores da agricultura" (BRASIL, 1946, s/p.). A LOEA foi a última do conjunto de normatizações da chamada Reforma Capanema, como ficou conhecido o conjunto de reformas educacionais realizadas durante a gestão do ministro da Educação Gustavo Capanema. Além da mencionada, foram publicadas as Leis Orgânicas do Ensino Secundário e do Ensino Industrial (1942); do Ensino Comercial (1943); do Ensino Primário e do Ensino Normal (1946) (NERY, 2010).

A Lei, primeira que regulamentou o ensino agrícola de nível médio, estabeleceu a instituição de três estabelecimentos de ensino agrícola: Escolas de Iniciação Agrícola, Escolas Agrícolas e Escolas Agrotécnicas, sendo estas últimas designadas a ofertar um ou mais cursos agrícolas técnicos (cursos de Agricultura, Horticultura, Zootecnia, Práticas Veterinárias, Indústrias Agrícolas, Laticínios e/ou Mecânica Agrícola). No entanto, somente a partir de 1947, “os Aprendizados e Escolas Agrícolas existentes foram reclassificados, enquadrando-se à nova conjuntura trazida pela LOEA. [...] Chegava ao fim o modelo de ensino agrícola primário materializado nos Aprendizados Agrícolas" (NERY, 2010, p. 272).

Seus objetivos continuavam a ter relações com aspectos econômicos, ao prever que o ensino agrícola deveria atender a interesses dos que trabalham no meio rural e aos interesses das propriedades ou estabelecimentos agrícolas, formando adequada e suficiente mão de obra (BRASIL, LOEA, 1946).

Decorridos quase 15 anos de aplicação da Lei Orgânica do Ensino Agrícola, entrou em
vigor a Lei no 4.024 , de 20 de dezembro de 1961 , que estabeleceu as diretrizes e bases da
Educação Nacional (LDB), estruturando o ensino em 3 (três) graus: primário, médio e
superior. O ensino médio, ministrado em dois ciclos (ginasial e colegial), abrangeu, entre
outros, os cursos secundário, técnico e de formação de professores para o ensino
primário e pré-primário; com relação ao ensino técnico de grau médio, a referida lei fixou
normas para o funcionamento dos cursos industrial, agrícola e comercial (SOBRAL,
2009, p. 84).

Somente em 1967, com a Reforma Administrativa dos Ministérios, todas as instituições de ensino passariam a ficar sob o comando do Ministério da Educação e Cultura, através do Departamento de Ensino Agrícola (DEA), desvinculando, dessa forma, o ensino agrícola profissional do Ministério da Agricultura.

\section{Gênese das escolas agrotécnicas federais e a escola agrotécnica federal Dom Avelar Brandão Vilela}

As décadas de 1960 e 1970 representaram mudanças profundas no setor agrícola nacional. Fatores como a expansão do financiamento agrícola, a adoção de políticas para exportação de grãos e importação de insumos e implementos, a adoção de uma política baseada no conceito de 
"Revolução Verde" impulsionara o aumento da produção agrária, subordinando "a agricultura dos países 'em desenvolvimento' aos complexos agroindustriais multinacionais” (SOBRAL, 2009, p. 87).

Nesse sentido, o ensino agrícola passa a ser orientado a partir da proposta do Departamento de Ensino Agrícola (DEA), que se baseava na metodologia do sistema escola-fazenda, "introduzido no Brasil em 1966, como consequência da implantação do Programa do Conselho TécnicoAdministrativo da Aliança para o Progresso" (SOBRAL, 2004, p. 29). Este sistema partia do princípio aprender a fazer e fazer para aprender, que tinha como principal objetivo associar o processo de aprendizagem à produção, através da vivência em áreas experimentais, onde pudesse ser realizado o trabalho voltado para as atividades agrícolas e pecuárias, sem deixar de lado, no entanto, o aprendizado teórico. "Em 1970, através do Ministério da Educação e Cultura, realiza-se a expansão desse sistema em toda a rede federal de ensino agrícola” (SOBRAL, 2004, p. 29).

Para isto, contribuiu a Coordenadoria Nacional do Ensino Agrícola (COAGRI), criada

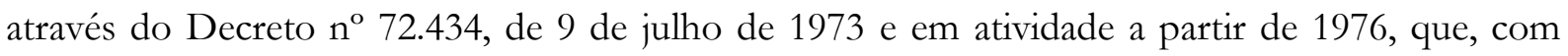
autonomia administrativa e financeira, tinha finalidade de prestar assistência técnica e financeira a estabelecimentos especializados em ensino agrícola. "A política de ensino agrícola implantada no período da COAGRI, foi responsável por sistematizar e garantir uma identidade, não construída até então, para essa modalidade de ensino" (SOBRAL, 2004, p. 32).

O Decreto $n^{\circ} 83.935$, de 4 de setembro de 1979, alterou a denominação das escolas agrícolas, que passaram a Escolas Agrotécnicas Federais, seguida do nome da cidade em que se localiza o estabelecimento, sendo facultado o nome de personalidade com a qual se identificava oficialmente a escola. De acordo com o anexo do referido decreto, 32 instituições passaram à nova denominação.

A Região do Submédio do Vale do São Francisco ${ }^{1}$, semiárido do nordeste brasileiro, não ficou de fora das transformações que reestruturavam as relações agropecuárias no Brasil. Até esse período, a região era marcada pela escassez de chuvas e pela falta de políticas de convivência com a seca, sendo mais recorrente a prática da agricultura de subsistência.

A partir do final da década de 1950, com a criação do Grupo de Trabalho para o Desenvolvimento para o Nordeste, tiveram início os debates em âmbito nacional sobre as consequências dos períodos de estiagem e as possibilidades para solucioná-las. Em um documento elaborado pelo grupo, era sugerida a implantação de sistemas de irrigação em áreas semiáridas,

\footnotetext{
1 O Vale Submédio do São Francisco está localizado na região sertaneja oeste do Estado de Pernambuco e norte do Estado da Bahia, abrangendo mais de 80 municípios.
} 
como forma de estimular a produção de alimentos, dando maior estabilidade ao trabalhador através da prática de uma agricultura que iria para além da subsistência (SOBEL, 2009).

Começava, então, a partir de 1960, a implantação de perímetros irrigados, sobretudo nas cidades de Petrolina (PE) e Juazeiro (BA). A criação da Superintendência do Desenvolvimento do Nordeste (Sudene), em 1959, contribuiu para a intensificação de ações nesse sentido, assim como futuramente a Superintendência do Vale do São Francisco (Suvale) e sua sucessora Companhia de Desenvolvimento dos Vales do São Francisco e Parnaíba (Codevasf), implantada em 1974, com objetivo de promover o desenvolvimento da região utilizando os recursos hídricos com ênfase na irrigação (SOBEL, 2009).

Até a década de 1980, já haviam sido implantados os projetos Bebedouro (1968), Nilo Coelho (1985), em Petrolina; Mandacaru (1971), Tourão (1979), Curaçá e Maniçoba (1980), em Juazeiro, que receberam incentivos do Governo Federal com "objetivo de assentar pequenos produtores em lotes com sistema de irrigação, criar mercado para os produtores da região, ofertar emprego, fornecer insumos agrícolas e adubos para que cada produtor pudesse se manter com autonomia" (ARAÚJO, 2013, p. 250-251).

A implantação dos primeiros projetos de irrigação começava a transformar a paisagem, a economia, a sociedade, o dia a dia das cidades. A aridez do solo aos poucos dava lugar a grandes áreas de produção de frutas, que futuramente ganhariam o mundo, tornando-se referência em agricultura irrigada.

Em Petrolina, o Perímetro Irrigado Senador Nilo Coelho foi um dos destaques, por possuir maior área irrigável. Justamente nas proximidades de um de seus núcleos, foi idealizada, ainda na década de 1980, através da articulação de políticos locais, a implantação de uma escola que fosse voltada para a formação de mão de obra para atuar em seu desenvolvimento.

Chapoulie e Briand (1994) chamam atenção para o fato de que a relação de agentes que são capazes de intervir no processo de criação e de transformação de um estabelecimento escolar deve permanecer sempre aberta e ao mesmo tempo destacam que um papel intermediário "mas bastante importante, é preenchido por responsáveis políticos (parlamentares e representantes locais), que são - ou foram - agentes da instituição escolar” (p. 28).

No caso da Escola Agrotécnica Federal Dom Avelar Brandão Vilela, um personagem foi determinante para sua criação: o deputado federal Osvaldo Coelho². Em 1985, mesmo ano em que

\footnotetext{
2 Membro da família Souza Coelho, de inquestionável influência política e econômica no município de Petrolina (PE), Osvaldo Coelho ingressou na vida política como deputado estadual, em 1955. Após três mandatos consecutivos, inaugurou sua presença na Câmara Federal nos anos 1970, onde exerceu oito mandatos, sendo eleito pela última vez em 2002. Durante seu percurso político, empenhou duas bandeiras principais: a da irrigação e da educação (SIQUEIRA, 2011).
} 
o Projeto Senador Nilo Coelho foi implantado, o deputado apresentou projeto de lei que autorizava a criação e implantação da Escola Agrotécnica Federal de Petrolina. A ideia tinha inspiração em uma viagem aos Estados Unidos, que Coelho realizara em 1967, para conhecer projetos de irrigação e observar a vida rural norte-americana (RODRIGUES, 2019). Lá, teria identificado determinada região onde havia várias escolas secundárias, que formavam técnicos em Agropecuária e ajudavam o desenvolvimento.

De acordo com levantamento presente em Rodrigues (2019), até a década de 1970, Petrolina contava com três estabelecimentos educacionais voltados para o ensino médio: uma escola comercial e duas escolas normais. Não havia nenhuma instituição voltada para o ensino agrícola.

Em sua justificativa para o Projeto de Lei n 6.736, que previa a implantação da Agrotécnica, publicada no Diário da Câmara dos Deputados, em 13 de novembro de 1985, Osvaldo Coelho falava dos projetos direcionados a resolver os problemas decorrentes da escassez de chuvas no sertão pernambucano do Vale do São Francisco, através de técnicas de captação, armazenamento e distribuição de água e consequente modernização do sistema agrícola. "É notório e comprovado, que a única alternativa capaz de assegurar colheitas fartas, trabalho bem remunerado e capital bem utilizado pelos agricultores nas zonas semi-áridas (sic), é a prática da agricultura irrigada" (BRASIL, 1985, p. 13.646).

O deputado destacava a potencialidade de transformação dos perímetros irrigados em importantes polos de desenvolvimento econômico e social, mas para isso salientava a necessidade de uma ação educativa que preparasse os agentes de produção, de maneira que se comportassem no trabalho produtivo como cidadãos agricultores. Em sua justificativa, Coelho não discorre sobre características de como deveriam ser estes cidadãos, mas relaciona diretamente a necessidade de criação de uma Escola Agrotécnica Federal em Petrolina ao desenvolvimento da agropecuária regional, já que os Mestres Agrícolas ou Operários Rurais qualificados por esta escola seriam capazes de se estabelecer como produtores e difundir o aprendizado.

Os técnicos formados seriam como vitrine, ao demonstrar para os demais de que maneira o conhecimento aplicado influenciaria nos resultados, estimulando a adoção de novas técnicas, de insumos, implementos, e consequente mudança das práticas agropecuárias. "A Escola será um verdadeiro centro de desenvolvimento rural na comunidade, não se limitando apenas ao ensino formal para aqueles que estão na faixa etária própria para ingresso na escola, mas também, para aqueles jovens e adultos que já se encontram na força de trabalho produtivo" (BRASIL, 1985, p. 
13.646). A argumentação do deputado Osvaldo Coelho enfatiza a relação entre a criação da Escola Agrotécnica com a qualificação de mão de obra específica para atuação nos perímetros irrigados.

Pelo exposto no projeto, a Escola Agrotécnica Federal de Petrolina estaria subordinada à Coordenação Nacional do Ensino Agropecuário (Coagri), assim como as mais de 30 unidades já em funcionamento no país, e teria como finalidade a oferta do primeiro e segundo graus profissionalizantes, com cursos de agropecuária, agricultura e economia doméstica, "devendo constituir-se em um centro de educação rural com vistas ao crescimento da agropecuária local e regional” (BRASIL, 1985, p.13.646).

Como visto, a idealização da Agrotécnica em Petrolina tinha relação direta com os arranjos produtivos locais e com o desenvolvimento econômico e agrícola pretendido através da implantação dos perímetros irrigados. Seria uma maneira de abastecer o mercado agrícola local de mão de obra preparada especificamente para esse trabalho, através da oferta pública de ensino profissionalizante. O projeto, no entanto, terminaria arquivado.

No ano seguinte, o deputado Osvaldo Coelho proporia ainda mais dois projetos de lei nesse sentido: o PL 7386/1986, que autorizava o poder executivo a criar a Escola Agrotécnica Federal de Araripina (PE) e o PL 7387/1986, que autorizava o poder executivo a criar a Escola Agrotécnica Federal de Salgueiro (PE). Ambos também foram arquivados.

Em 1988, o pleito finalmente seria atendido. Através do Decreto $n^{\circ} 96.598$, de 25 de agosto, publicado pelo Governo Federal, era criada a Escola Agrotécnica Federal Dom Avelar Brandão Vilela (EAFDABV), subordinada à Secretaria de Ensino de $2^{\circ}$ Grau do Ministério da Educação. Tinha como finalidade ministrar o ensino de segundo grau profissionalizante, constituindo-se "em um centro de educação rural com vistas ao crescimento da agropecuária local e regional” (BRASIL, 1988).

Assim como no projeto apresentado em 1985, que terminaria arquivado, o decreto de criação da Agrotécnica Dom Avelar Brandão Vilela enfatiza não apenas a constituição de uma escola, mas sim de um "centro de educação rural". Compreende-se que o termo se refere a uma instituição que não limitaria sua atuação aos seus muros, mas trabalharia no sentido de inserir-se no contexto agropecuário local, de forma a tornar-se referência.

Chapoulie e Briand (1994) destacam como aspecto importante da dimensão institucional dos fatos escolares a maneira como determinada instituição insere-se no espaço. "Cada estabelecimento está submetido às exigências de uma localidade que ele mesmo contribui, aliás, para definir, e que possui, ao mesmo tempo, uma dimensão demográfica, econômica, política, assim como uma dimensão institucional” (p. 18). 
A EAFDABV foi localizada no Núcleo 4 do Projeto Irrigado Senador Nilo Coelho, tendo o próprio perímetro como laboratório e como forma de estabelecer um diálogo entre as necessidades da produção econômica local com o processo educativo. Além dessa relação econômica com o espaço, o apoio da Codevasf foi decisivo na escolha do local de implantação, ao doar o terreno para estabelecimento da escola. Ainda mais: "custeou o corpo docente até a contratação do quadro efetivo e doou os equipamentos de irrigação para o curso de prática em agricultura irrigada" (RODRIGUES, 2019, p. 110).

A inauguração, no entanto, aconteceu meses antes, em 17 de junho, em uma solenidade festiva, com a presença do presidente da República, José Sarney, do então governador de Pernambuco, Miguel Arraes, do deputado Osvaldo Coelho, de prefeitos e outras autoridades locais. Sarney enfatizou a necessidade da criação de Escolas Técnicas e da formação de mão de obra qualificada, citando como exemplo o Estado da Califórnia (EUA), que na época tinha duas universidades e 125 escolas técnicas (PRESIDENTE, 1988).

A Escola Agrotécnica Federal Dom Avelar Brandão Vilela iniciou de fato suas atividades em 1989, com a oferta apenas do curso técnico em Agropecuária. Um de seus diferenciais, o nome não se referia ao local de pertencimento, como a maioria das Agrotécnicas até então, mas seria uma homenagem ao homem que é considerado pioneiro em relação à agricultura irrigada no Vale do São Francisco. O alagoano Avelar Brandão Vilela ${ }^{3}$ tomou posse como terceiro bispo de Petrolina, em dezembro de 1946, ainda aos 34 anos de idade. Entre suas ações, criou o Posto de Colonização Agrícola de Petrolina, instalou a Campanha Nacional de Educação Rural, além de realizar as Semanas Ruralistas (CARVALHO, 2010).

As Escolas Agrotécnicas se estabeleceram como uma forma de escolarização ligada à modernização do setor agrícola e sua crescente necessidade de mão de obra especializada. Importante frisar que, mesmo com a confluência de alguns elementos que compõem o campo educacional, em âmbito nacional e local, relativos à criação de Escolas Agrotécnicas, cada estabelecimento se constitui de uma maneira própria, a partir da relação entre seus agentes e o contexto em que estão inseridos.

\footnotetext{
${ }^{3}$ Avelar Brandão Vilela nasceu em 1912, em Viçosa (AL). Foi ordenado padre em 1935, em Aracaju (SE), onde exerceu os cargos de professor de Psicologia, Português e Literatura Luso-Brasileira; secretário do bispado, capelão, cônego. Foi eleito bispo de Petrolina (PE) em 1946. Chegou ao Piauí em 1956, como segundo arcebispo da Diocese de Teresina, onde permaneceu até 1971, quando foi transferido para Salvador (BA). Em 1973 foi escolhido pelo papa Paulo VI como cardeal da Igreja de Roma. Faleceu em 1986, na capital da Bahia (CARVALHO, 2010).
} 


\begin{abstract}
Mais do que segmentações que se designam por níveis, graus, ramos, tipos, etc, a escolarização é dotada de processos institucionais que a estruturam. São esses processos que podem fornecer melhor explicações, sejam sobre as relações definidas como pedagógicas ou institucionais, os seus agentes: professores, alunos, funcionários, o seu conteúdo: disciplinas e organização curricular, a sua política: administração e gestão, ou mesmo os recursos materiais e os elementos simbólicos da escola (RODRIGUES, 2009, p. 288).
\end{abstract}

Como ressaltam Chapoulie e Briand (1994), tal análise não pode se limitar aos objetivos explícitos dos fundadores e reformadores dos sistemas escolares. "A comparação entre situações nacionais evidencia rapidamente seus limites, já que o desenvolvimento desta ou daquela forma de escolarização é acompanhada sempre de um conjunto de outras mudanças sociais, como a urbanização, a industrialização, etc” (p. 30).

Através das informações analisadas sobre o processo de instalação da Escola Agrotécnica Federal Dom Avelar Brandão Vilela, em Petrolina (PE), e de como se deu a institucionalização do ensino profissionalizante agrícola no Brasil, é possível perceber que há uma confluência de elementos nessa gênese, como o fato de o movimento para a sua criação ter laços estreitos com o desenvolvimento econômico local. No entanto, faz-se ainda necessário um estudo mais aprofundado de seus elementos fundadores.

\title{
Considerações finais
}

Compreender o contexto histórico em que surgiu e se desenvolveu o ensino técnicoprofissional no Brasil, especialmente o ensino voltado para a prática agrícola, e o que motivou as transformações das formas de escolarização a ele relacionadas, ao longo dos anos, foi de fundamental importância para traçar os percursos fundadores da Escola Agrotécnica Federal Dom Avelar Brandão Vilela, em Petrolina (PE).

Nesta trajetória, foi possível observar as normatizações do ensino agrícola e sua constante relação com as mudanças e apelos econômicos em curso no país, desde sua primeira regulamentação, em 1910, que instituiu os Aprendizados e os Patronatos Agrícolas, até a instituição das Escolas Agrotécnicas.

Vale ressaltar a história dos Aprendizados Agrícolas no Brasil enquanto forma de escolarização, pois esta se encontra na gênese da constituição do ensino técnico agrícola e do ensino rural no país. Além deste tema, a própria forma de escolarização e cultura escolar desenvolvidas a partir da instituição das Escolas Agrotécnicas e, em especial da Escola Agrotécnica Federal Dom Avelar Brandão Vilela, podem constituir-se em novas propostas de estudo. 


\section{Referências}

ARAÚJO, Guilherme José Ferreira; SILVA, Marlene Maria. Crescimento econômico no Semiárido brasileiro: o caso do polo frutícola Petrolina/Juazeiro. Caminhos de Geografia, v.14, n.46, p.246264. Junho, 2013. Disponível em:

http://www.seer.ufu.br/index.php/caminhosdegeografia/article/view/18291/12824. Acesso em: 15 jul. 2021.

BOURDIEU, Pierre. Os usos sociais da ciência: por uma sociologia clínica do campo científico. Tradução: Denice Barbara Catani. São Paulo: Editora UNESP, 2004. 86 p.

BOURDIEU, Introdução a uma Sociologia Reflexiva. In: BOURDIEU, Pierre. O Poder Simbólico. Tradução: Fernando Tomaz. Rio de Janeiro: Bertrand Brasil, 2012, p. 17-58.

BRASIL. Decreto $n^{0} 7.566$, de 23 de setembro de 1909. Cria nas capitais dos Estados da República Escolas de Aprendizes Artífices, para o ensino profissional primário gratuito. Disponível em: https://www2.camara.leg.br/legin/fed/decret/1900-1909/decreto-7566-23-setembro-1909525411-publicacaooriginal-1-pe.html. Acesso em: 20 jun. 2021.

BRASIL. Decreto n 8.319, de 20 de outubro de 1910. Cria o Ensino Agronômico e aprova o respectivo regulamento. Disponível em: https://www2.camara.leg.br/legin/fed/decret/19101919/decreto-8319-20-outubro-1910-517122-publicacaooriginal-1-pe.html. Acesso em: 2 jul. 2021.

BRASIL. Decreto $n^{\circ} 24.115$, de 12 de abril de 1934. Dispõe sobre a organização definitiva dos estabelecimentos de ensino elementar de agricultura, subordinados à Diretoria do Ensino Agrícola, do Departamento Nacional, da Produção Vegetal e dá outras providências. Disponível em https://www2.camara.leg.br/legin/fed/decret/1930-1939/decreto-24115-12-abril-1934512582-publicacaooriginal-1-pe.html. Acesso em: 2 jul. 2021.

BRASIL. Decreto-Lei no 9.613, de 20 de agosto de 1946. Lei Orgânica do Ensino Agrícola. Disponível em: https://www2.camara.leg.br/legin/fed/declei/1940-1949/decreto-lei-9613-20agosto-1946-453681-publicacaooriginal-1-pe.html. Acesso em: 2 jul. 2021.

BRASIL. Decreto $n^{\circ} 72.434$, de 9 de julho de 1973. Cria a Coordenação do Ensino Agrícola COAGRI - no Ministério da Educação e Cultura, atribuindo-lhe autonomia administrativa e financeira e dá outras providências. Disponível em:

https://www2.camara.leg.br/legin/fed/decret/1970-1979/decreto-72434-9-julho-1973-420902publicacaooriginal-1-pe.html. Acesso em: 5 jul. 2021.

BRASIL. Decreto $n^{\circ} 83.935$, de 4 de setembro de 1979. Altera a denominação dos estabelecimentos de ensino que indica. Disponível em: https://www2.camara.leg.br/legin/fed/decret/1970-1979/decreto-83935-4-setembro-1979433451-publicacaooriginal-1-pe.html. Acesso em: 5 jul. 2021.

BRASIL. Decreto $n^{\circ}$ 96.598, de 25 de agosto de 1988. Cria a Escola Agrotécnica Federal Dom Avelar Brandão Vilela, em Petrolina, Estado de Pernambuco, e dá outras providências. Disponível em: http://www2.camara.leg.br/legin/fed/decret/1988/decreto-96598-25-agosto-1988-447290publicacaooriginal-1-pe.html. Acesso em: 14 jun. 2021. 
BRASIL. Projeto de Lei n ${ }^{\circ} 6.736$, de 1985. Autoriza a criação e implantação da Escola Agrotécnica Federal de Petrolina, no Estado de Pernambuco. Distrito Federal: Congresso Nacional, [1985]. Disponível em:

https://www.camara.leg.br/proposicoesWeb/fichadetramitacao?idProposicao=231213. Acesso em: 5 jul. 2021.

CARVALHO, Sônia Maria dos Santos. Dom Avelar Brandão Vilela: uma biografia histórica. 2010. Dissertação (Mestrado em História do Brasil) - Universidade Federal do Piauí, Teresina, 2010. Disponível em:

http://www.leg.ufpi.br/subsiteFiles/mesthist/arquivos/files/Dissertacoes/Dissertacao_SONIA. pdf. Acesso em: 10 jul. 2021.

CHAPOULIE, Jean-Michel; Briand, Jean-Pierre. A instituição escolar e a escolarização: uma visão de conjunto. Tradução Julieta B. Desaulniers. Educação \& Sociedade, n. 47, p. 11-55, abr. 1994.

CUNHA, Luiz Antônio. O ensino de ofícios nos primórdios da industrialização. $2^{a}$ ed., São Paulo: Editora UNESP; Brasília, DF: FLACSO, 2005. Livro eletrônico, edição Kindle. 4641 posições.

NERY, Marco Arlindo Amorim Melo. Pelos caminhos de Deméter: os aprendizados agrícolas federais e as políticas para o ensino agrícola primário no início do século XX (1910-1947). 2010. Tese (Doutorado em Educação) - Universidade Federal da Bahia, Salvador, 2010. Disponível em: http://repositorio.ufba.br/ri/handle/ri/11910. Acesso em: 3 jul. 2021.

NÓVOA, António. História da educação: percursos de uma disciplina. Análise Psicológica. Lisboa, n. 4, p. 417-434, out./dez 1996.

PRESIDENTE Sarney otimista com a irrigação. Jornal de Juazeiro, Juazeiro, BA, Ano 15, n. 981, p.3, 21/22 jun. 1988.

RODRIGUES, José Roberto Gomes. Formas de escolariz̨ação secundária e sócio-gênese de uma instituição escol ar: o Ginásio Ruy Barbosa em Juazeiro, BA (1953-1963). 2009. Tese (Doutorado em Educação) - Faculdade de Educação, Universidade de São Paulo, São Paulo, 2009.

RODRIGUES, Ricardo José Pereira. Osvaldo Coelho. Brasília: Câmara dos Deputados, Edições Câmara, 2019.

SARNEY inaugura escola Agrotécnica na Região. Jornal de Juazeiro, Juazeiro, BA, Ano 15, n. 980, capa, 17/20 jun. 1988.

SIQUEIRA, Geovani. Osvaldo Coelho: A trajetória política de um visionário. Jornal Gazzeta do São Francisco, Petrolina, PE, Ano 15, n 2.161, 03 a 05 de maio de 2011. Suplemento especial.

SOBEL, T. F. Desenvolvimento territorial: uma avaliação das políticas adotadas no polo Petrolina-Juazeiro entre os anos 1960-2000. História Econômica \& História de Empresas, v. 12, n. 1, p.101-129, 2009. Disponível em: https://doi.org/10.29182/hehe.v12i1.13. Acesso em: 7 jul. 2021. 
SOBRAL, Francisco José M. A formação do técnico em Agropecuária no contexto da agricultura familiar do oeste catarinense. Tese (Doutorado em Educação) - Faculdade de Educação, Universidade Estadual de Campinas, Campinas, SP, 2004. Disponível em:

http://www.repositorio.unicamp.br/handle/REPOSIP/253006. Acesso em: 27 jun. 2021.

SOBRAL. Retrospectiva Histórica do Ensino Agrícola no Brasil. Revista Brasileira de Educação Profissional e Tecnológica - MEC, v.2, n.2, p.78-95, 2009. Disponível em: https://doi.org/10.15628/rbept.2009.2953. Acesso em: 27 jun. 2021. 